\title{
Analysis of the properties of exergy and biodiversity along an estuarine gradient of eutrophication
}

\author{
J.C. Marques ${ }^{a, *}$, M.Â. Pardal ${ }^{a}$, S.N. Nielsen ${ }^{b}$, S.E. Jørgensen ${ }^{b}$ \\ a IMAR (Institute of Marine Research), Department of Zoology, University of Coimbra, 3000 Coimbra, Portugal \\ ${ }^{\mathrm{b}}$ Royal Danish School of Pharmacy, Institute A, Environmental Chemistry Section, Universitetsparken 2, \\ $D K-2100$ Copenhagen $\emptyset$, Denmark
}

Accepted 16 April 1997

\begin{abstract}
Benthic eutrophication often gives origin to qualitative changes in marine and estuarine ecosystems, for example the shift in primary producers, often followed by changes in species composition and trophic structure at other levels. Through time such modifications may determine a selected new trophic structure. The development of structural dynamic models will allow to simulate such changes, using goal functions to guide ecosystem behaviour and development. The selection of other species and other food web may then be accounted by a continuous optimisation of model parameters according to an ecological goal function. Exergy has been applied in structural dynamic models of shallow lakes, and appears to be one of the most promising approaches. Theoretically, exergy is assumed to become optimised during ecosystems development, and ecosystems are supposed to self organise towards a state of an optimal configuration of this property. Exergy may then constitute not only a suitable system-oriented characteristic to express natural tendencies of ecosystems evolution, but also a good ecological indicator of ecosystems health. Biodiversity is also an important characteristic of ecosystems structure, constituting a powerful and traditional concept, which was found to be suitable to test the intrinsic ecological significance of exergy. We examined the properties of exergy (exergy and specific exergy) and biodiversity (species richness and heterogeneity) along an estuarine gradient of eutrophication, testing the hypothesis that they would follow the same trends in space and time. This hypothesis was validated in a certain extent, with exergy, specific exergy and species richness decreasing as a function of increasing eutrophication, but heterogeneity responding differently. Biodiversity measurements and their interpretation appeared subjective. Exergy and specific exergy may be a suitable alternative, that could be used as goal functions in ecological models and as holistic ecological indicators of ecosystems integrity. Nevertheless, since exergy and specific exergy showed to respond differently to ecosystems seasonal dynamics, it is advisable to use both
\end{abstract}

\footnotetext{
* Corresponding author. Tel./fax: + 35139 23603; e-mail: jcmimar@cygnus.ci.uc.pt
} 
complementary. The method proposed by Jørgensen et al. (1995) to estimate exergy, which takes into account the biomass of organisms and the thermodynamic information due to genes, appeared to be operational. There is nevertheless an obvious need for the determination of more accurate (discrete) weighing factors to estimate exergy from organisms biomass. We propose to explore the assumption that the dimension of active genomes, which are primarily a function of the required genetic information to build up an organism, are proportional to the relative contents of DNA in different organisms. (C) 1997 Elsevier Science B.V.

Keywords: Exergy; Biodiversity; Eutrophication

\section{Introduction}

Changes in environmental factors often give origin to qualitative alterations in the ecosystems (e.g. species composition, biodiversity). For example, it has been observed that benthic eutrophication in estuaries and coastal lagoons may determine a shift from rooted plants communities, dominated by slow growing species, like the eelgrass Zostera, towards free floating (or partially free floating) faster growing macroalgae, like Chaetomorpha, Enteromorpha, or Ulva (Hartog, 1994), as well as changes in the biomass and species composition of macroalgae (Lavery et al., 1991). Actually, with regard to competition between macrophytes and macroalgae communities in coastal ecosystems, nutrient enrichment of the water column tend apparently to favour macroalgae adaptive strategies (Hartog, 1994). This shift in primary producers may of course determine changes in species composition at other trophic levels (e.g. macrofauna composition), and through time such modifications may give origin to a selected new trophic structure.

To model such changes describing the development of ecosystems as a response to changes in external factors, it is necessary to include in the models the qualitative trophic alterations through time, and to direct the adaptational and selective processes.

The traditionally established models of aquatic ecosystems are not adequate to predict when qualitative changes, like shifts in species composition at various trophic levels, will take place (Nielsen, 1995). This is mostly due to the fact that measurements typically carried out to account for and to assess impacts over the ecosystems (e.g. biomass and production measurements) are not able to capture the qualitative ongoing changes. In fact, as denoted above, in aquatic ecosystems the impact of eutrophication, for instance, is often not expressed as an increase or decrease in production.

Nevertheless, through the development of structural dynamic models (Jørgensen, 1993; Nielsen, 1992, 1995), which has recently been started, it seems possible to incorporate in ecological models the type of changes described above. This new generation of models may be able to include and describe changes in species composition and trophic structure of ecosystems in general (Nielsen, 1994, 1995), allowing to improve the existing models, not only in the sense of increasing their predictive capability, but also approaching a better understanding of ecosystems behaviour, and consequently a better environmental management.

In structural dynamic models, instead of using the most common modelling strategy, which consists of including in the model more trophic levels and more types of organisms to represent each level, it has been tried to use goal functions to guide ecosystem behaviour and development, allowing in addition to save time and to bypass problems caused by models increased complexity (Nielsen, 1995; Straskraba, 1983). In this case, the selection of other species and the selection of other food web may be accounted by a change of model parameters according to an ecological goal function. This allows to introduce in the models parameters that change as a function of changing forcing functions and conditions of state variables, optimising by a stepwise approach the ability of the ecosystem to move away from thermodynamic equilibrium.

Goal functions are mathematical algorithms which act as quality indicators of ecosystems, constituting emergent properties arising from self organisation processes in the run of their development. In the last decade, several functions have been proposed as possible goal functions in 
ecosystems. Exergy, a concept derived from thermodynamics (Jørgensen and Mejer, 1979, 1981), which can be seen as energy with a build in measure of quality, appears to be one of the most promising approaches, showing a possible role in expressing shifts in species composition and trophic structure in shallow lakes ecosystems (Jørgensen, 1988; Nielsen, 1990, 1995).

Exergy is assumed to become optimised during ecosystems development, which are supposed to self organise towards a state of an optimal configuration of this property (Jørgensen, 1992). In such case, exergy could constitute not only a suitable system-oriented characteristic for natural tendencies of ecosystems evolution, but also a good ecological quality indicator. Nevertheless, there are theoretical and practical problems that must be solved before this challenging concept can be used both in models for the management of nature and as a holistic ecological quality indicator.

In this paper we approach three major questions:

- What are the relationships between exergy and other more conventional ecological indicators like biodiversity?

- In practice, how to estimate exergy values and make this goal function operational?

- In what extent are exergy estimated values really capable to elucidate about the state of ecosystems?

A comprehensive field data set on the spatial and temporal variation of benthic communities along a gradient of eutrophication was used to effectuate exergy estimations and biodiversity measurements. The point was that, although difficult to define precisely, the concept of biodiversity (even remaining somehow illusory) is in it self powerful and intuitive, constituting a good available tool to test the ecological significance of goal functions like exergy. Actually, although there might be other factors involved, it is normally accepted that, within a given ecosystem, polluted areas (e.g. eutrophicated) will exhibit less complex communities, with a less complex trophic structure, and lower biodiversity than non polluted areas. Biodiversity may then be comprehended as a quality indicator of the state of the ecosystem. On the other hand, in what way could exergy (as holistic ecological quality indicator) be effective in discerning between distinct states of the ecosystem when differences are relatively subtle? We tested the hypothesis that exergy and biodiversity would follow the same trends in space and time.

\section{Materials and methods}

The benthic communities in the Mondego estuary (Portuguese western coast) were monitored during a yearly cycle, from February 1993 to February 1994. Samples of macrophytes, macroalgae, and associated macrofauna were taken fortnightly at different sites, during low water, along an estuarine gradient of eutrophication in the south arm of the estuary (Fig. 1), from a non eutrophicated zone, where a macrophytes community (Zostera noltii) is present, up to a heavily eutrophicated zone, in the inner areas of the estuary, from where the macrophytes disappeared while Enteromorpha spp. (green macroalgae) blooms have been observed during the last decade. In this area, as a pattern, Enteromorpha spp. biomass normally increases from early winter (February/March) up to July, when an algae crash usually occurs. A second but much less important algae biomass peak may normally be observed in September followed by a decrease up to the winter.

Simultaneously, corresponding to each biological sample, the following cnironmental factors were determined: salinity (g $\mathrm{I}^{-1}$ ), temperature $\left({ }^{\circ} \mathrm{C}\right), \mathrm{pH}$, oxygen dissolved, ammonia, silica, chlorophyll a, nitrites, nitrates, and phosphates $\left(\mathrm{mg} \mathrm{l}^{-1}\right)$, for the water, and organic matter contents $\left(\mathrm{g} \mathrm{m}^{-2} \mathrm{afdw}\right)$, for the sediments.

The organisms collected (macrophytes, macroalgae, and macroinvertebrates) were almost always identified to the species level, and their biomass determined ( $\mathrm{g} \mathrm{m}^{-2} \mathrm{afdw}$ ).

Data on each site and each sampling date were used for exergy calculations and biodiversity measurements. To estimate exergy we used the method based upon the thermodynamic information due to genes proposed by Jørgensen et al. 


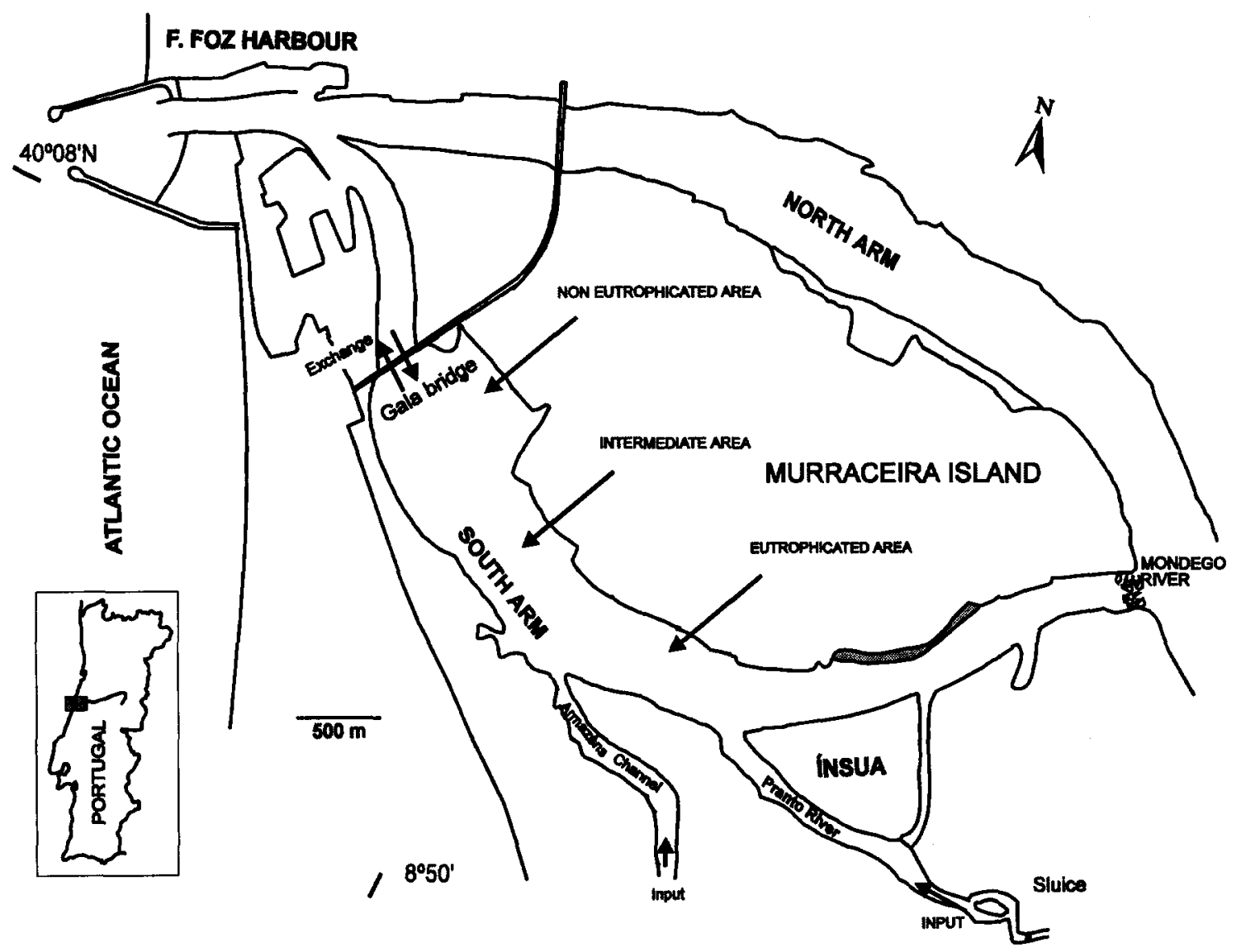

Fig. 1. The Mondego estuary: it consists of two arms, north and south, with very different hydrographic characteristics. The north arm is deeper, while the south is almost silted up in the upstream areas. The water circulation in the south arm is mostly due to tides and to the freshwater input of a tributary, the Pranto River, which is artificially controlled by a sluice. The south arm of the estuary is eutrophicated, and the gradient of eutrophication is indicated.

(1995), considered by the authors as the best candidate for exergy calculations of ecosystems, which take into account the organisational level of organisms.

Exergy can be computed from (Mejer and Jørgensen, 1979):

$\mathrm{Ex}=R T \sum_{i=0}^{n}\left[C i \ln \left(C i / C i_{\mathrm{eq}}\right)+\left(C i-C i_{\mathrm{eq}}\right)\right]$

Where $R$ is the gas constant, $T$ is the absolute temperature, $\mathrm{Ci}$ is the concentration in the system of component $i, C i_{\text {eq }}$ is the corresponding concentration of component $i$ at thermodynamic equilibrium, and index $O$ indicates the inorganic compounds of the considered element.
From this expression it can be derived that (Jørgensen et al., 1995) an approximate estimation of exergy may be given by:

$\mathrm{Ex}=T \sum_{i=1}^{i=n} \beta i \times C i$

Where $T$ is the absolute temperature, $C i$ is the concentration in the ecosystem of component $i$ (e.g. biomass of a given taxonomic group or functional group), $\beta i$ is a factor able to express roughly the quantity of information embedded in the biomass. Detritus is chosen as reference level, i.e. $\beta i=1$, and exergy in biomass of different types of organisms being expressed in detritus energy equivalents. 
Table 1

The evolution of g DNA/cell, number of genes, and number of cell types (approximate figures are given) for different organisms

\begin{tabular}{|c|c|c|c|c|}
\hline Organisms & $10^{-12} \mathrm{~g}$ DNA/cell & Number of genes & Number of cell types & Weighing factor \\
\hline Detritus & 0 & 0 & 0 & 1 \\
\hline Bacteria & 0.005 & 600 & $1-2$ & 2.7 \\
\hline Algae & 0.009 & 850 & $6-8$ & 3.4 \\
\hline Yeast & 0.02 & 2000 & $5-7$ & 5.8 \\
\hline Fungus & 0.03 & 3000 & $6-7$ & 9.5 \\
\hline Sponges & 0.1 & 9000 & $12-15$ & 26.7 \\
\hline Plants, trees & $\ldots$ & $10000-30000$ & - & $30 \cdots 90^{4}$ \\
\hline Jellyfish & 0.9 & 50000 & 23 & 144 \\
\hline Nemertineans & $-\ldots$ & .... & $\ldots$ & $144^{\prime \prime}$ \\
\hline Insects & $\ldots$ & -- & - & $144^{: 1}$ \\
\hline Crustaceans & & - & - & $144^{: 1}$ \\
\hline Annelid worms & 20 & 100000 & 60 & 287 \\
\hline Molluses & $\ldots$ & -- & -. & $287^{\mathrm{a}}$ \\
\hline Echinoderms & -.. &.- & & $144^{i}$ \\
\hline Fish & 20 & $100000-120000$ & 70 & $287 \quad 344$ \\
\hline Birds & -- & 120000 & - & 344 \\
\hline Amphibians & $-\ldots$ & 120000 & - & 344 \\
\hline Reptiles & $-\ldots$ & 120000 & - & 344 \\
\hline Mammals & 50 & 140000 & 100 & 402 \\
\hline Human & 90 & 250000 & 254 & 716 \\
\hline
\end{tabular}

The concentration of each organism was multiplied by the proposed weighing factor to estimate exergy. The weighing factor accounts for the information embodied in the organism in addition to the simple biomass $\left(\mathrm{g} \mathrm{m}^{-2}\right.$ afdw). For this purpose, it is assumed that detritus (organic matter contents in sediments) do not contain relevant structural information. Sources: Li and Grauer (1991) in Jorgensen (1995).

"These values were not provided by any source but assumed as reasonable.

Through time, the variation of exergy in an ecosystem may therefore be considered as resulting from the variation of the biomass and of the information builded in one unit of biomass (expressing the quality of the biomass):

$$
\Delta \mathrm{Ex}_{\mathrm{tot}}=\Delta \mathrm{B}_{\mathrm{iom}} \times \beta I+\Delta \beta I \times \mathrm{B}_{\mathrm{iom}}
$$

If the total biomass $\left(\mathrm{B}_{\text {tot }}\right)$ in the system remains constant through time, then the variation of exergy $\left(\mathrm{Ex}_{\mathrm{tot}}\right)$ will be a function of only the structural complexity of the biomass or, in other words, of the information embedded in the biomass. It may then be called specific exergy ( $\mathrm{SpEx}$ ), expressed as exergy per unit of biomass. For each instant, specific exergy is given by:

$\mathrm{SpEx}=\mathrm{Ex}_{\mathrm{tot}} /$ Biom $_{1 \mathrm{ot}}$

Values of exergy and specific exergy were calculated from the biomass of the different organisms ( $\mathrm{g} \mathrm{m}^{-2} \mathrm{afdw}$ ) through the use of weighing factors able to discriminate different 'qualities' of biomass
(Table 1). For this purpose, taking into account the available set of weighing factors, data on organisms biomass was pooled as a function of higher taxonomic levels (e.g. Phylum or Class). An overview of the major taxonomic groups contributing to the exergy in this system is provided in Table 2 .

Regarding biodiversity, we took into consideration the species richness and the heterogeneity (species richness + evenness). For each date measurements were effectuated taking into account data on the number of individuals (ind $\mathrm{m}^{-2}$ ) per species, and on species biomass ( $\mathrm{g} \mathrm{m}^{-2} \mathrm{afdw}$ ). In both cases, only macrofauna was taken into consideration.

From the considerable assortment of indices designed by ecologists, we considered suitable the use of the Margalef index (I), to compute species richness, and of Shannon-Wienner's index $\left(\mathrm{H}^{\prime}\right)$ based on the information theory, to compute heterogeneity (Legendre and Legendre, 1984; Magurran, 1988). It comes: 
Table 2

Major contributors to the exergy in the Mondego estuary benthic communities along the gradient of eutrophication

\begin{tabular}{lcccc}
\hline Contributors & $\begin{array}{l}\text { Non eutrophi- } \\
\text { cated area }\end{array}$ & $\begin{array}{l}\text { Intermediate eu- } \\
\text { trophicated area }\end{array}$ & $\begin{array}{l}\text { Eutrophicated area-before the } \\
\text { algae crash }\end{array}$ & $\begin{array}{l}\text { Eutrophicate area-after the } \\
\text { algae crash }\end{array}$ \\
\hline Enteromorpha & 2.099 & 28.211 & 264.642 & 1.273 \\
+ Ulva & & & & \\
Other macroaal- & 16.141 & 2.138 & 6.152 & 0.165 \\
gae & & & & 0.000 \\
$Z$ nolti leafs & 128.368 & 0.000 & 0.000 & 0.000 \\
$Z$ nolti roots & 87.975 & 0.000 & 0.000 & 0.000 \\
$Z$. nolti-total & 216.343 & 0.000 & 0.000 & 0.000 \\
Anthozoa & 0.003 & 0.000 & 0.000 & 0.002 \\
Sipunculia & 0.001 & 0.001 & 0.001 & 0.001 \\
Nemertinea & 0.005 & 0.003 & 0.005 & 0.002 \\
Oligochaeta & 0.128 & 0.031 & 0.010 & 0.846 \\
Polychaeta & 1.254 & 0.709 & 0.569 & 13.240 \\
Mollusca & 63.950 & 14.192 & 31.195 & 3.419 \\
Crustacea & 1.3720 & 1.088 & 14.945 & 0.001 \\
Insecta & 0.007 & 0.006 & 0.009 & 0.000 \\
Echinodermata & 0.000 & 0.000 & 0.000 & 0.000 \\
Pisces & 0.000 & 0.006 & 0.034 & \\
\hline
\end{tabular}

For the non eutrophicated and intermediate eutrophicated areas, the average anual biomass $\left(\mathrm{g} \mathrm{m}^{-2}\right)$ of each is given. For the eutrophicated area, the average biomass $\left(\mathrm{g} \mathrm{m}^{-2}\right)$ of each group before and after the algae crash is given.

$\mathrm{I}=(n-1) / \log _{\mathrm{e}} N$

where $n$ is the number of species found and $N$ is the total number of individuals, and:

$\mathrm{H}^{\prime}=-\sum_{i=1}^{n} \mathrm{p}_{i} \log \mathrm{p}_{i}$

where $n$ is the number of species, and $p_{i}$-is the proportion of the biomass of species $i$ in a community were the species proportions are $\mathrm{p}_{1}, \mathrm{p}_{2}$, $\mathrm{p}_{3}, \ldots \mathrm{p}_{i}, \ldots, \mathrm{p}_{n}$.

Both exergy and biodiversity values constituted static estimations of dynamic qualities of ecosystems. Therefore, to examine their properties as ecological indicators, a moving average (using prior, present, and following dates) was applied to each value, in order to adjust potential bias due to sampling.

\section{Results}

The spatial and temporal variation of exergy, specific exergy, species richness, and heterogeneity were analysed in order to test our previous hy- pothesis that these ecological indicators would capture changes in benthic communities along the gradient of eutrophication providing a similar picture of the ecosystem.

With regard to exergy (Fig. 2A), as hypothesised, values were consistently higher in the Zostera noltii community than in the eutrophicated areas. Also, exergy values were higher in the most heavily eutrophicated area when compared with the intermediate eutrophicated area, specially during spring and early summer 1993. This was obviously related with the intensity of the Enteromorpha bloom, which determined much higher values for total biomass in the most eutrophicated area (Fig. 2C).

Specific exergy was found to be consistently higher in the Zostera noltii community than in the eutrophicated areas until late spring (Fig. 2B), in accordance with our previous hypothesis, but the picture changed completely and values became higher in the eutrophicated areas. This was obviously a function of the macroalgae crash in the eutrophicated areas (between the 22th of June and the 6th of July 1993), which determined not only 

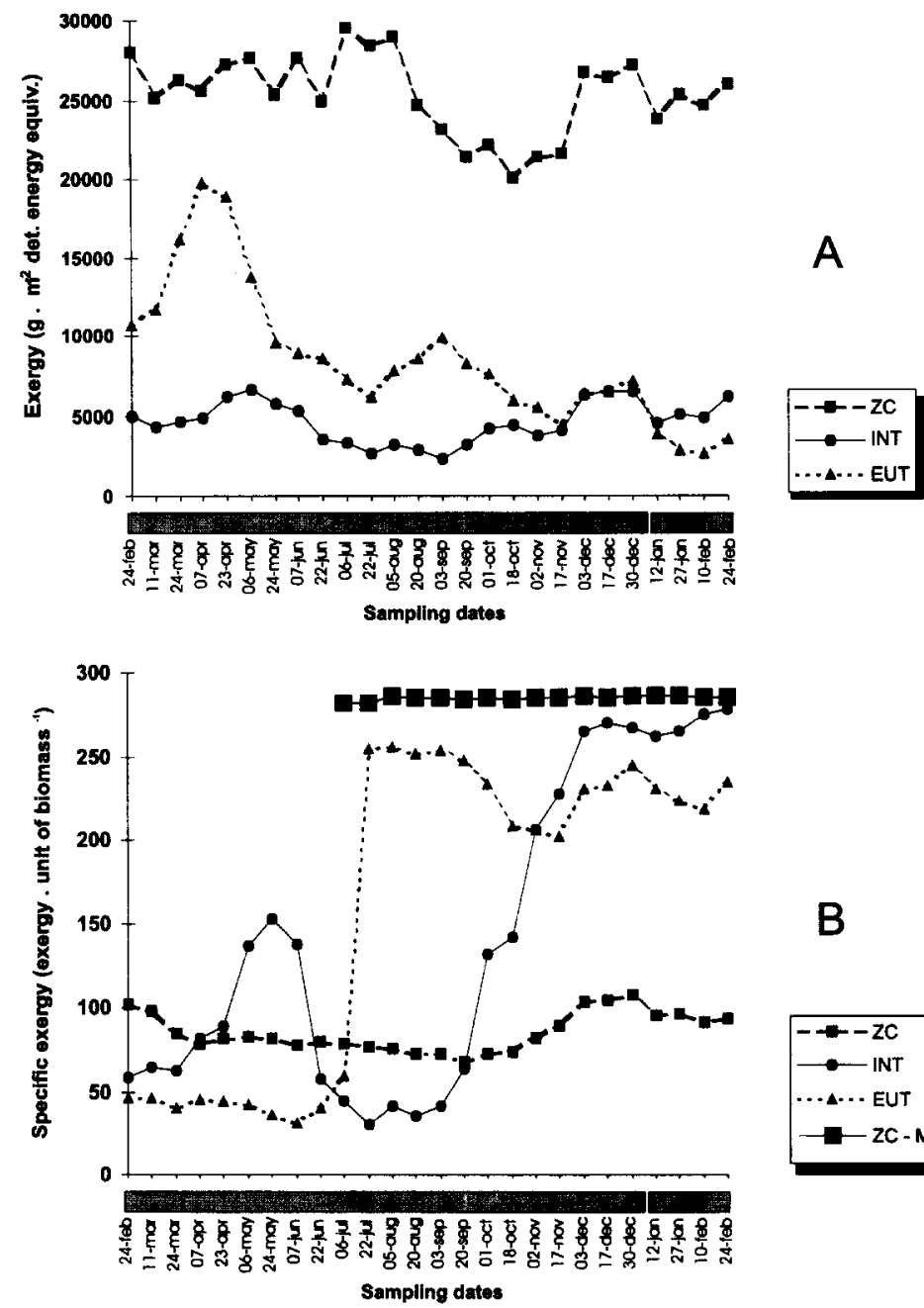

B

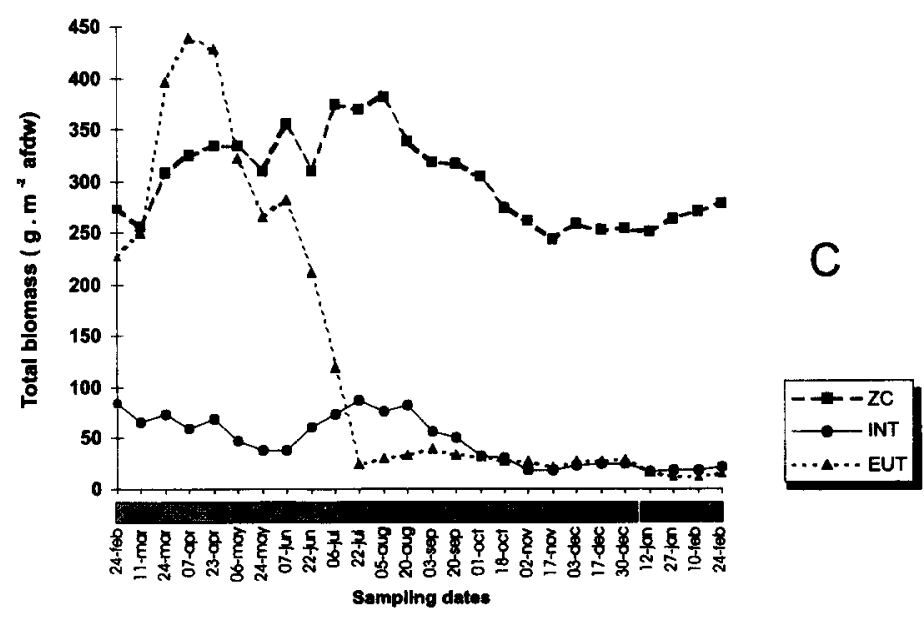

Fig. 2. 
a drastic reduction of the total biomass (Fig. 2C) but also a change from a primary production based situation towards a detritus based food web. Therefore, since total biomass values after the 6th of July consisted basically of animals (consumers), primarily deposit feeders and detritic feeders (e.g. annelid worms and crustaceans), it is clear that the abrupt increase of specific exergy in the eutrophicated areas after the algae crash do not reflect any augmentation of the structural complexity of the community, but simply the different quality of the biomass involved in the calculations. This becomes immediately obvious if we compare the values of specific exergy estimated for the non eutrophicated area (Zostera community), taking into account only macrofauna, with the values for eutrophicated areas (Fig. 2B). Actually, regarding the Zostera community (data from after the 6th of July), accounting for the primary producers and the consumers specific exergy is lower than in the eutrophicated areas. But if we account only for the consumers it is clearly higher, following the same pattern from before the algae crash, in agreement with our previous hypothesis. Hence, specific exergy may shift very drastically as a function of yearly dynamics (like in communities dominated by $r$ strategists), providing a spatial and temporal picture that may be not related with the long term evolution and integrity of the system.

With regard to biodiversity, the variation of species richness and of heterogeneity (species richness + evenness) along the gradient of eutrophication provided quite different pictures (Fig. 3). Through time, as we hypothesised, species richness was consistently higher in the non eutrophicated area (Zostera community), decreasing along the gradient of eutrophication (Fig. 3A). On the contrary, heterogeneity was always higher in the eutrophicated areas (Fig. 3B), except for the decrease observed in the most heavily eutrophicated area in early summer 1993, which was clearly related with the algae crash (see the drastic reduction of total biomass in Fig. 2C).

The observed spatial variation of heterogeneity, which was not in agreement with our hypothesis, originates in the fact that the Shannon-Wienner's index integrates two components, the number of species (species richness) and their relative abundances (evenness). Therefore, although species richness decreased as a function of increasing eutrophication, as we expected, the extremely high concentration (dominance) of a few species (e.g. Hydrobia ulvae, a detritic feeder and epiphytic grazer gastropod, and Cerastoderma edule, a filter feeder bivalve) in the Zostera community, probably due to the abundance of nutritional resources, decreased species evenness, and consequently heterogeneity values. In this case, lower values of heterogeneity must be interpreted as expressing higher biological activity, and not as a result of environmental stress (Legendre and Legendre, 1984).

In what extent did exergy and biodiversity followed the same trends, as we hypothesised, decreasing from the non eutrophicated area of the estuary up to the heavily eutrophicated ones?

Taking into account the yearly data series for each site along the eutrophication gradient (non eutrophicated, intermediate eutrophicated, eutrophicated) (Fig. 4), exergy and specific exergy were significantly correlated $(P \leq 0.05)$ providing a similar picture from the system. Values were consistently higher and more stable in the non eutrophicated area as the compared with the eutrophicated ones. The comparison of yearly data series ( $t$-test, $P \leq 0.05$ ) showed that through exergy values it was possible to distinguish between the three situations considered. Nevertheless, through specific exergy, differences between the intermediate eutrophicated and eutrophicated areas were not significant, which suggests that ex-

\footnotetext{
Fig. 2. Spatial and temporal variation of exergy (A) specific exergy (B), and total biomass (C) in non eutrophicated (Zostera noltii community) (ZC), intermediate eutrophicated (INT) and eutrophicated (EUT) areas. For specific exergy (B), we indicate the values estimated from the total biomass, taking into account the whole period, and the values estimated only from the macrofaunal biomass, for the period from the 6th of July 1993 to the 24th of February 1994. In this last case, the aim was to allow the comparison of specific exergy between the Zostera community (non eutrophicated area) and the eutrophicated areas of the estuary, where after the algae crash the total biomass consisted basically of animals.
} 


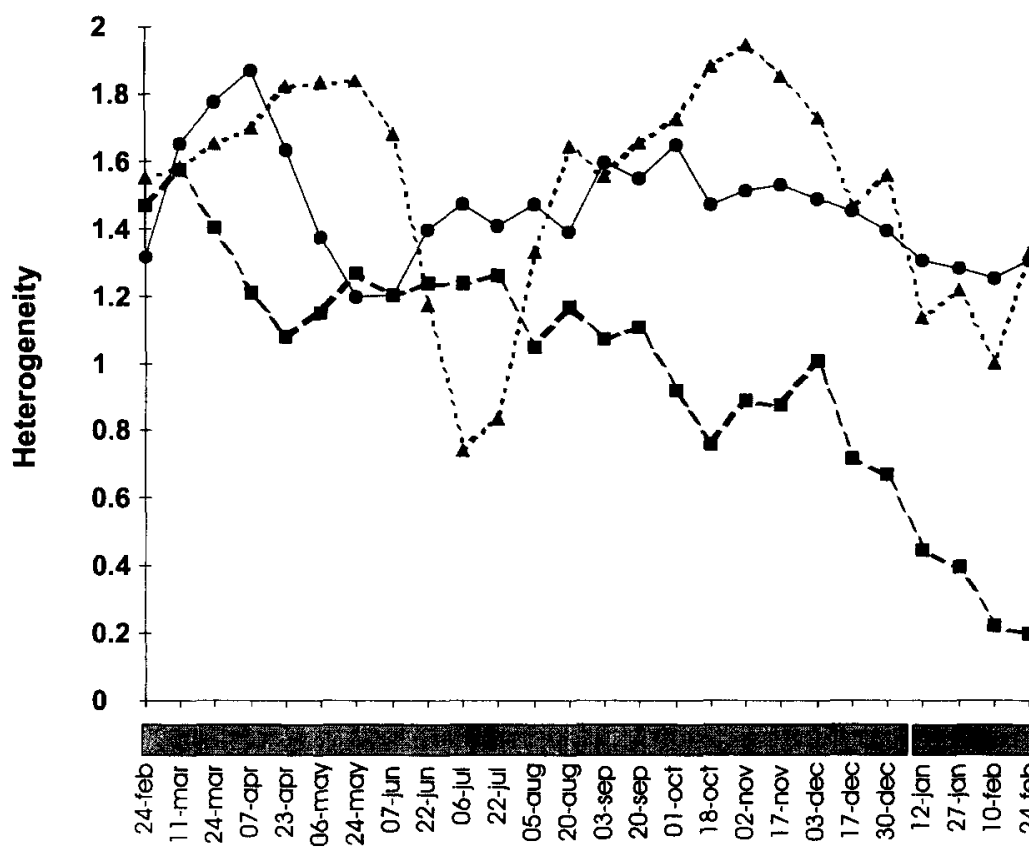

Sampling dates

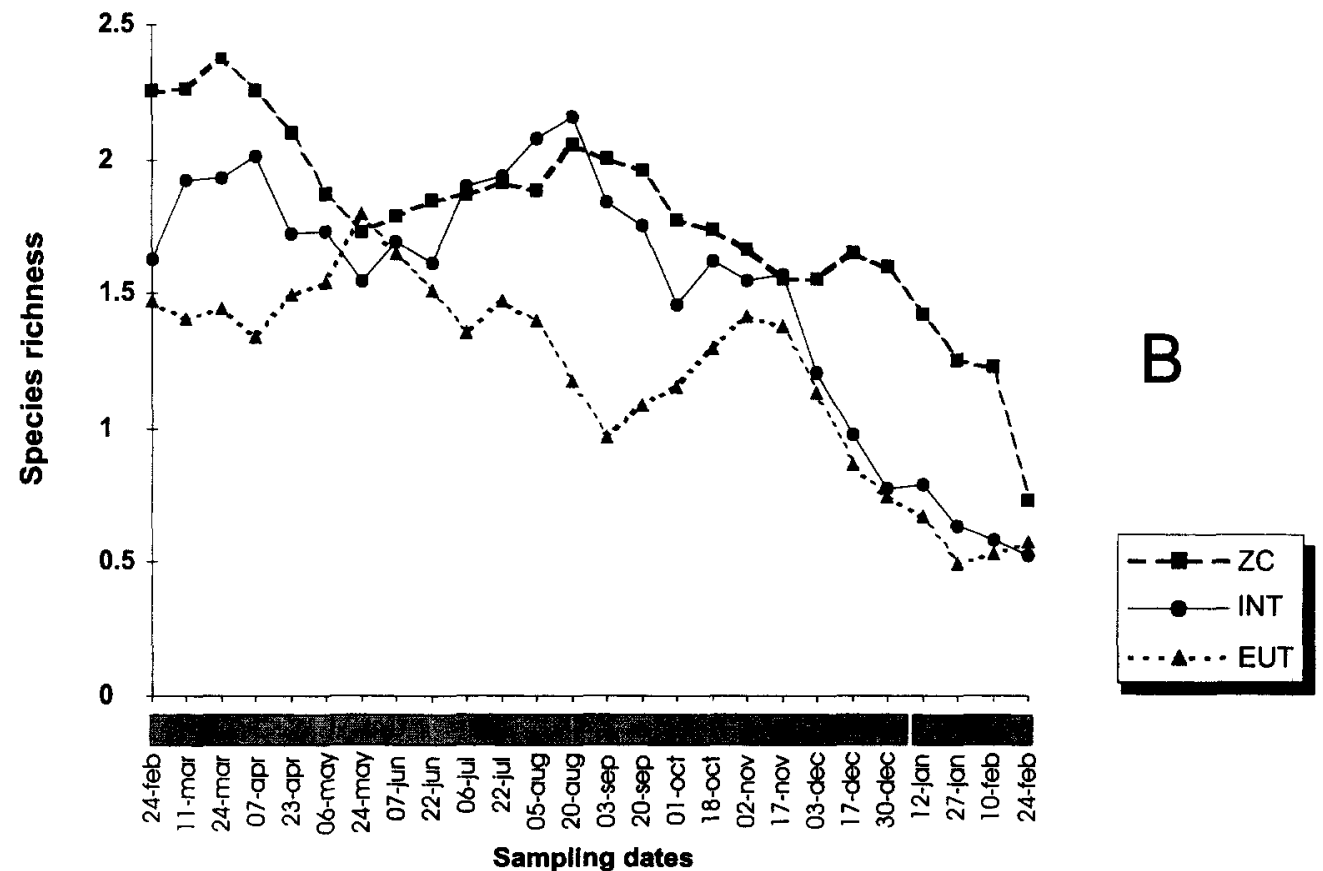

Fig. 3. Spatial and temporal variation of heterogeneity (A), species richness (B in non eutrophicated (ZC), intermediate eutrophicated (INC) and eutrophicated (EUT) areas. Heterogeneity was computed using the Shannon-Wienner's index, and species richness using the Margalef's index. 

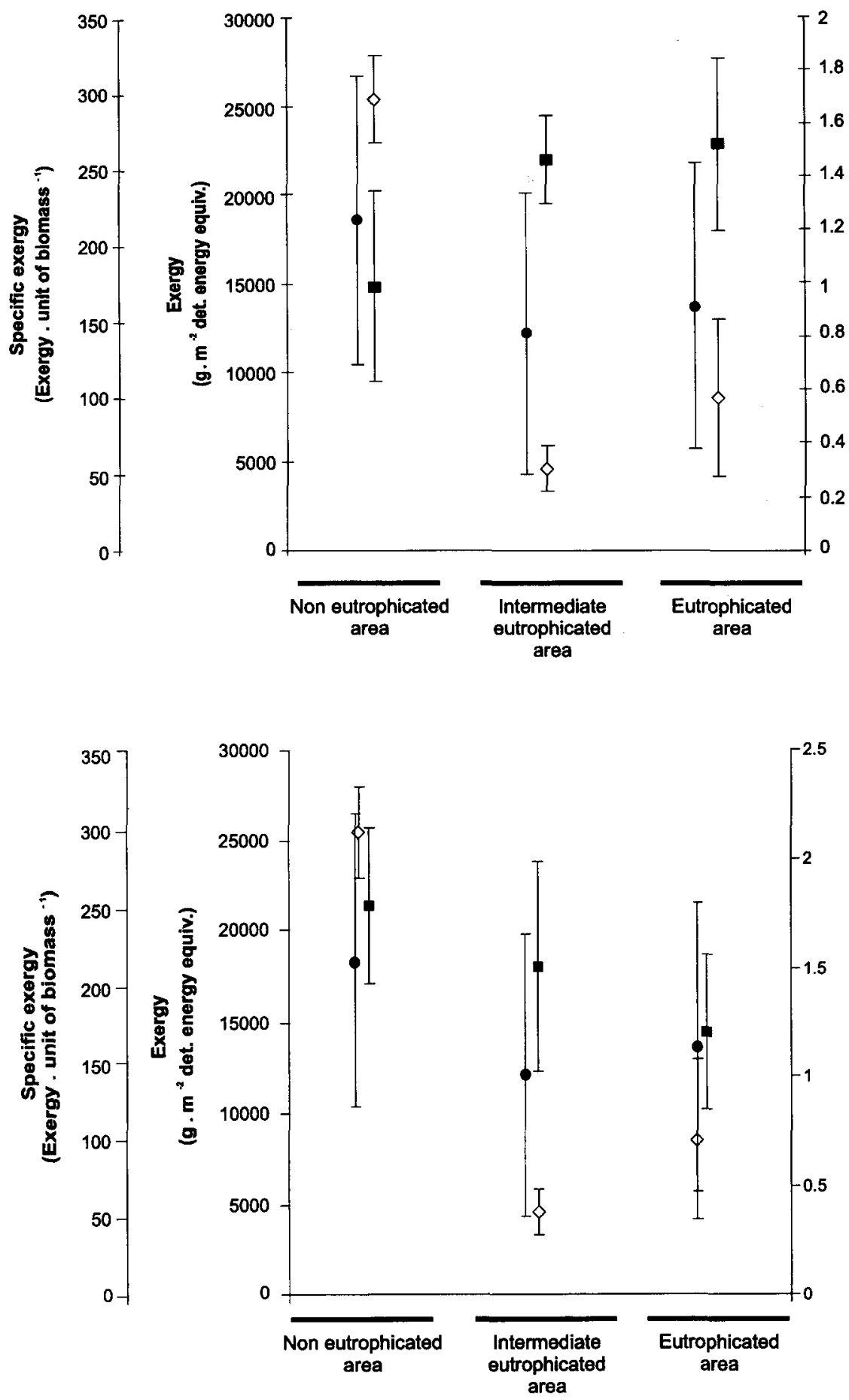

Fig. 4. Variation of exergy and specific exergy in comparison with heterogeneity (A) and species richness (B) along the gradient of eutrophication gradient. For each situation, respectively non eutrophicated (ZC), intermediate eutrophicated (INT), and eutrophicated (EUT), we indicate the average values and the standard deviation, taking into account the entire yearly data set. The spatial variation of exergy and specific exergy was significantly correlated $(r=0.59 ; P \leq 0.05)$. The spatial variation of heterogeneity was not significantly correlated neither with exergy or specific exergy $(r=-0.48$ and $r=0.38$, respectively; $P \leq 0.05)$. The spatial variation of species richness was significantly correlated with both exergy and specific exergy $(r=0.60$ and $r=0.90$, respectively; $P \leq 0.05$ ). 
ergy might be more sensitive to detect subtle differences.

Species richness and exergy were significantly correlated $(P \leq 0.05)$, following a similar pattern, both decreasing from non eutrophicated to eutrophicated areas (Fig. 4B). On the contrary, heterogeneity and exergy appeared negatively correlated (although not significantly), providing a totally distinct picture of the benthic communities along the eutrophication gradient (Fig. 4A). This obviously resulted from the properties of the heterogeneity measure, as explained above.

Similar results were obtained comparing the patterns of variation of species richness, heterogeneity and specific exergy. Species richness and specific exergy appeared clearly positively correlated $(P \leq 0.05)$ (Fig. 4B), while the patterns of variation of heterogeneity and specific exergy showed to be distinct (Fig. 4A). Moreover, from the comparison of yearly data series ( $t$-test, $P \leq$ 0.05 ), heterogeneity values were not significantly different in the intermediate eutrophicated and eutrophicated areas, and therefore did not permit to discriminate relatively subtle differences.

\section{Discussion}

The hypothesis that exergy and biodiversity would follow the same trends in space and time was validated with regard to species richness, but not for heterogeneity. Actually, exergy, specific exergy, and species richness responded as hypothesised, decreasing from non eutrophicated to eutrophicated areas, but heterogeneity responded in the opposite way, showing the lowest values in the non eutrophicated area. On the other hand, both exergy and species richness were able to grade situations presenting relative subtle differences, but specific exergy and heterogeneity did appear to be less sensitive. Moreover, as ecological indicator, heterogeneity (measured using the Shannon-Wienner's index) appeared to be of more subjective interpretation. Thus, although biodiversity may be considered as an important property of ecosystem structure, the relative subjectivity of its measurements and their interpretation constitutes an obvious problem. Exergy and specific exergy appeared to be capable to elucidate about the state of the ecosystem (benthic communities) along the gradient of eutrophication, and therefore they may constitute suitable system-oriented characteristics, and a good indicators of ecosystem integrity. The fact that, as we observed, specific exergy may shift very drastically as a function of the system yearly dynamics, providing a spatial and temporal picture different from exergy, makes advisable to use both complementary.

With regard to exergy estimations, the method proposed by Jørgensen et al. (1995), which takes into account both biomass and the thermodynamic information due to genes appears to be operational. Nevertheless, the proposal of using the number of genes and not the amount of DNA per cell to express this information may be not practical. Moreover, there is an obviously need (Table 1) for the determination of more accurate (discrete) weighing factors to estimate exergy from organisms biomass.

For this purpose, genome dimension is assumed to be suitable as an efficient marker to characterise the structural complexity of organisms. Genetic mapping available in published data is however very scarce, since most of the organisms in biotic systems have not been characterised owing to the long time procedures and high costs involved in the molecular work of gene analysis. A more practical approach must therefore be undertaken.

The dimension of the active genome is primarily a function of the required genetic information to build up an organism, and this genetic information is contained in the DNA. Therefore, we reasonably assume that the dimension of the active genome is roughly proportional to the relative contents of DNA in the organisms. Since several correlations are possible involving the quantity of DNA in the organisms and their level of complexity (e.g. cells dimension and DNA contents, histological complexity and DNA contents), it seems plausible to elaborate scales of numerical parameters, determined through such correlations, in order to make possible a correspondence between numerical values and complexity of different taxonomic groups. This may be achieved through the isolation and purification of cell nucleus from 
representative organisms, and determination of its DNA contents. Even if, in a certain extent, data produced suffers from reliability when compared with genetic analysis, this will not be a problem since the aim is to generate conceptual exergistic relationships between different kinds of organisms, where their complexity is accounted as an indirect measure of the quality of the biomass, and therefore proportional to the distance of that matter to thermodynamic equilibrium.

Biodiversity may be seen as the full range of biological diversity from intraspecific genetic variation to the species richness, connectivity and spatial arrangement of entire ecosystems at a landscape level scale (Solbrig, 1991). If we accept this biodiversity concept, then exergy, as systemoriented characteristic and as ecological indicator of ecosystem integrity, may encompass biodiversity. Moreover, exergy estimations, as described above, really imply to transport information through scales, from the genetic to the ecosystem level, accounting not only for the biological diversity, but also for the evolutionary complexity of organisms, and ecosystem emergent properties arising from self organisation processes.

In general, the observations indicate that the communities around both the Zostera and Enteromorpha populations represent stabilised levels at either end of an eutrophication gradient. The intermediate eutrophicated area appeared clearly not stable, presenting always low values for total biomass (Fig. 2C). Recruitment of new faunal elements can in principle occur both from the Zostera and the Enteromorpha communities, but neither of these elements will be able to establish permanently, probably due to lack of proper substratum. In other words, the area is too disturbed, and organisms establishment is not stimulated by this disturbance. This would be the case for an intermediate disturbance, which actually seems to correspond to the situation in the Enteromorpha community before the algae crash.

The algae crash has the characteristics of a catastrophic event, bringing the eutrophicated area in the same situation as the intermediate eutrophicated area, i.e. low exergy and high specific exergy due to low biomasses (consisting primarily of animals) (Fig. 2 A, B, and C).
Meanwhile, the Enteromorpha community is able to recover from this situation as indicated by recent results (Pardal, pers. com.), whereas the situation in the intermediate eutrophicated area remains the same.

\section{Conclusions}

The hypothesis that exergy and biodiversity would follow the same trends in space and time was validated in a certain extent, with exergy, specific exergy and species richness decreasing as a function of increasing eutrophication, but heterogeneity responding differently.

Although biodiversity may be considered an important property of ecosystems structure, the subjectivity of its measurements and their interpretation constitutes a problem. Alternatively, exergy and specific exergy may constitute suitable system-oriented characteristics for natural tendencies of ecosystems evolution, as well as good indicators of ecosystems integrity.

Exergy and specific exergy may respond differently to systems seasonal dynamics, providing different spatial and temporal pictures. It is therefore advisable to use both complementary.

With regard to exergy estimations, the method proposed by Jørgensen et al. (1995), which takes into account the biomass of organisms and the thermodynamic information due to genes appears to be operational. Nevertheless, the use of the amount of DNA per cell nucleous instead of the number of genes may be more practical to characterise different organisms. In fact, genetic mapping available in published data is very scarce, and most of the organisms in biotic systems have not been characterised owing to the long time procedures and high costs involved in the molecular work of gene analysis.

There is an obvious need for the determination of more accurate (discrete) weighing factors to estimate exergy from organisms biomass, and we propose to explore the assumption that the dimension of the active genome is proportional to the relative contents of DNA in the organisms. 


\section{Acknowledgements}

This paper was supported by the Programme MAST II (MAS 2 CT 92 0036) and by JNICT, Portugal. The authors are indebted to all the colleagues from the University of Coimbra who assisted in field and laboratory work. A very special thanks goes for Maria Gabriel Fontes, for the precious help in data storage and management.

\section{References}

Hartog, C., 1994. Suffocation of a littoral Zostera bed by Enteromorpha radiata. Aquat. Bot. 47, 21-28.

Jørgensen, S.E., Mejer, H., 1979. A holistic approach to ecological modelling. Ecol. Model. 7, 169-189.

Jørgensen, S.E., Mejer, H., 1981. Exergy as a key function in ecological models. In: Mitsch, W., Bosserman, R.W., Klopatek, J.M. (Eds.), Energy and Ecological Modelling. Developments in Environmental Modelling, Vol. 1. Elsevier, Amsterdam, pp. 587-590.

Jørgensen, S.E., 1988. Use of models to account for changes in species composition. Ecol. Model. 41, 117-126.

Jørgensen, 1992. Integration of ecosystems theories: a pattern. Kluver Academic Publishers, 393 p.

Jørgensen, S.E., 1993. State of the art of ecological modeling. In: McAleer, M. (Ed.), Proceedings of the International
Congress on Modelling and Simulation, University of Western Australia, pp. 455-481.

Jørgensen, S.E., Nielsen, S.N., Mejer, H., 1995. Emergy, environ, exergy and ecological modelling. Ecol. Model. 77, $99-109$.

Lavery, P.S., Lukatelich, R.J., McComb, A.J., 1991. Changes in the biomass and species composition of Macroalgae in a eutrophic estuary. Estuarine Coastal Shelf Sci. 33, 1-22.

Legendre, L., Legendre, P., 1984. Ecologie numérique. I-- Le traitement multiple des données écologiques. Paris, Masson. 1-197.

Magurran, A.E., 1988. Ecological diversity and its measurement. Croom Helm, London, 179 p.

Mejer, H., Jørgensen, S.E., 1979. Energy and ecological buffer capacity. In: Jørgensen, S.E. (Ed.), State-of-the-Art of Ecological Modelling, Environmental Sciences and Applications, Proceedings 7th Conference Ecological Modelling, International Society for Ecological Modelling, pp. 829846.

Nielsen, S.N., 1990. Application of exergy in structural dynamic modelling. Verh. Int. Verein. Limnol. 24, 641-645.

Nielsen, S.N., 1992. Strategies for structural dynamic modelling. Ecol. Model. 63, 91-101.

Nielsen, S.N., 1994. Modelling structural dynamical changes in a Danish shallow lake. Ecol. Model. 73, 13-30.

Nielsen. S.N., 1995. Optimisation of exergy in a structural dynamic model. Ecol. Model. 77. 111 122.

Solbrig, O.T. (Ed.), 1991. From genes to ecosystems: A research agenda for biodiversity, IUBS-SCOPE-UNESCO, Cambridge, Mass, $124 \mathrm{p}$.

Straskraba, M., 1983. Cybernetic formulation of control in ecosystems. Ecol. Model. 18, 85-98. 